\title{
RESEARCH EFFORTS ON INTELLIGENT TRANSPORTATION SYSTEM IN NIGERIA: DEVELOPMENT OF TRIP PLANNING MODELS
}

\author{
0. O. Adeleke1,*, Y. A. Jimoh², I. T. Yusuf 3, S. S. Kolo4, O.D. Jimoh'5, A. R. Anwar6, \\ H. S. Abdulrahman ${ }^{7}$ and S. Oyewobi ${ }^{8}$ \\ 1, 2, 3, 6, DEPARTMENT OF CIVIL ENGINEERING, UNIVERSITY OF ILORIN, ILORIN, KWARA STATE NIGERIA.

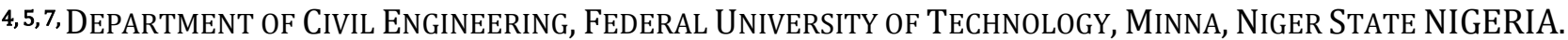

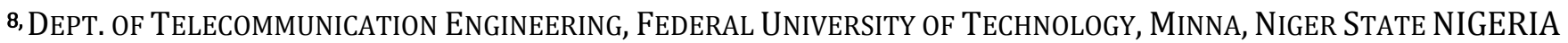 \\ E-mail addresses:1 adeleke.oo@unilorin.edu.ng,2dryajimoh@yahoo.com,3ityusuf@yahoo.com, \\ 4s.kolo@futminna.edu.ng,5odjimoh@futminna.edu.ng,6saiyadianwar@gmail.com, \\ 7 abdul.hassan@futminna.edu.ng,8 oyewobistephen@futminna.edu.ng
}

\begin{abstract}
The critical situation of unwelcome frustration experienced by urban trip makers and roadside dwellers alike, calls for a very strong push by all stakeholders in the transportation sector to enhance the service performance of transportation facilities using Intelligent Transportation Systems (ITS). Needed strategies for successful ITS implementation in both developed and developing nations, include but not limited to policy formulation and planning, funding of ITS projects, development and deployment of research products, system performance measurement, optimization of the performance of existing infrastructure, capacity building, etc. which could be much promoted with research efforts. Advanced Public Transportation System (APTS) and Advanced Traveller Information System (ATIS) categories as products of research on ITS were developed with data derived from urban trip makers on captive corridors, both in Ilorin, Kwara State and Minna, Niger State, Nigeria. The fundamental basis and status of the research activities targeted at developing and deploying the ITS in Nigeria are highlighted in the paper.
\end{abstract}

Keywords: Intelligent Transportation Systems, Policy formulation, Research product deployment, Funding, System performance optimization

\section{INTRODUCTION}

\subsection{ITS Definition and Techniques}

The transportation challenges experienced in most Nigerian urban centers include traffic congestion, inadequate provision of carriers for commuters in quantity and timeliness, poor traffic management, poor condition of roads, attitudinal behavior of drivers, among others. This unwanted situation calls for a strong push by stakeholders in the transportation sector to assure the deserved service performance of transportation facilities using Intelligent Transportation System (ITS) [1]. ITS combine advances in information systems, communications, sensors, and advanced modeling and algorithms to provide and also improve the performance of transportation systems for enhanced safety, efficiency and serviceability. It also assures reduction in urban congestion, while accommodating the growth in transit ridership and freight/goods movement without the need for investment in the physical facilities. ITS encompasses all elements of the transportation system - infrastructure, vehicles and users, and its application or deployment could either be vehicle or human focused or both together. The technologies generally include (a) sensors to detect traffic conditions and vehicle motions (b) wireless communications between roadway infrastructure and vehicles and among different vehicles (c) data processing and storage (d) electromechanical actuators and (e) software to implement and optimize the desired behaviours in any or all of these subsystems or the whole transportation systems. Table 1 is a list of ITS applications and technologies. 
Since the introduction of ITS, there has been a proliferation of interest by the various stakeholders (government and industry) because of the assured benefits, especially in effective urban traffic congestion amelioration as well as serve as effective options for improving traffic conditions without expansion of the fixed facilities subsystem [1]. Indeed, many public transportation agencies in the developed countries, such as US, Japan, Korea, Britain, Canada and a few in the developing countries, such as India, Indonesia, Brazil and Nigeria (but to a lesser extent), have been applying ITS for technological advancements to improve their services [2-8]. It is also evidenced that ITS deployment can impact transportation system performance in six key goal areas. These include Safety - improved safety; Mobility - decreased travel time, decreased cost, improved trip planning; Efficiency - improved emergency response; Productivity - increased productivity, on-time delivery; Energy and Environment - decreased fuel consumption, decreased air pollution; Customer Satisfaction - congestion relief and increased reliability $[10,11]$.

However, much more benefits but less costly are probable, if other research efforts, especially based on trip information management are incorporated in the case of developing countries. This group of countries lacks the sophisticated ICT, instrumentation and even finance.

The aim of this study is to give a highlight on the development and deployment of trip information ITS techniques with a view to stimulate the research effort products in tackling the mobility challenges in a developing nation, Nigeria.

\subsection{Theory: ITS Deployment Strategies}

The strategies that should be considered for ITS deployment are enumerated subsequently.

\subsubsection{Policy and planning}

Planning plays a fundamental role in the national, state, or local government vision for its future, which makes it mandatory that policies should be developed on how to incorporate ITS products and services in transportation planning process in order to assure the desired amelioration of related challenges in motorized and nonmotorized urban movement. There should be planning documents for ITS, such as a National/regional ITS architecture, an ITS strategic plan, a concept of operations, a long-range transportation improvement plan and the use of traffic analysis tools to assist in evaluating alternatives [11].

Table 1: ITS applications technologies

\begin{tabular}{|c|c|c|c|}
\hline Functionalities & Categories & Enabling Technologies & User Services \\
\hline $\begin{array}{l}\text { Information and } \\
\text { guidance (for } \\
\text { decision making) }\end{array}$ & $\begin{array}{l}\text { Advanced Traveler, } \\
\text { Information Systems } \\
\text { (ATIS) }\end{array}$ & $\begin{array}{l}\text { In-vehicle navigation systems, Way-side } \\
\text { or terminal display systems, Interactive } \\
\text { telephone messaging systems, } \\
\text { Transmitters, Traffic message television } \\
\text { channels/radiofrequencies dedicated to } \\
\text { relaying real-time, traffic reports, Internet }\end{array}$ & $\begin{array}{l}\text { Pre-trip travel information, En- } \\
\text { route driver information, En- } \\
\text { route transit information, } \\
\text { Traveler services information, } \\
\text { Route guidance, Ride matching } \\
\text { and reservations, Personalized } \\
\text { public transit, Emergency } \\
\text { notification and personal } \\
\text { security, Impairment alert }\end{array}$ \\
\hline $\begin{array}{l}\text { Traffic } \\
\text { Controlling and } \\
\text { directing }\end{array}$ & $\begin{array}{l}\text { Advanced Vehicle } \\
\text { Control Systems (AVCS) }\end{array}$ & $\begin{array}{l}\text { Road-side electronic sensors, In-vehicle } \\
\text { sensors, Traffic signal controls } \\
\text { Computerized in-vehicle safety device }\end{array}$ & $\begin{array}{l}\text { Traffic control, Longitudinal } \\
\text { collision avoidance, Lateral } \\
\text { collision avoidance, Intersection } \\
\text { crash warning and control, } \\
\text { Vision enhancement for crash } \\
\text { avoidance, Pre-crash restraint } \\
\text { deployment }\end{array}$ \\
\hline $\begin{array}{l}\text { Automation and } \\
\text { efficiency } \\
\text { enhancement }\end{array}$ & $\begin{array}{l}\text { Advanced Public } \\
\text { Transportation Systems } \\
\text { (APTS), Commercial } \\
\text { Vehicle Operations } \\
\text { (CVO), Advanced Rural } \\
\text { Transportation Services } \\
\text { (ARTS) }\end{array}$ & $\begin{array}{l}\text { Automatic vehicle location equipment, } \\
\text { Traffic modeling software, GIS real time } \\
\text { traffic maps Electronic cards }\end{array}$ & $\begin{array}{l}\text { Travel demand management, } \\
\text { Electronic payment services, } \\
\text { Commercial vehicle pre- } \\
\text { clearance, Commercial vehicle } \\
\text { administrative processes, } \\
\text { Commercial fleet management, } \\
\text { Public transportation } \\
\text { management, Fully automated } \\
\text { vehicle operation }\end{array}$ \\
\hline $\begin{array}{l}\text { Surveillance and } \\
\text { monitoring }\end{array}$ & $\begin{array}{l}\text { Advanced Traffic } \\
\text { Management Systems } \\
\text { (ATMS) }\end{array}$ & $\begin{array}{l}\text { Video imaging processing systems, Probe } \\
\text { technologies, Automatic incident detection } \\
\text { systems }\end{array}$ & $\begin{array}{l}\text { Incident management, Safety } \\
\text { monitoring, Automated roadside } \\
\text { safety inspections }\end{array}$ \\
\hline
\end{tabular}


Figure 1 shows the various aspects involved in transportation planning which can also guide in the implementation of plan, design, development and deployment of ITS in any transportation network. These have been developed into the standard transportation planning process scheme (manual) for organized ITS deployment. The manual includes provision for (i) defining visions and goals (ii) identifying improvement/implementation strategies (iii)evaluation and prioritization of strategies (iv)project development (v) system operations and (vi) system performance monitoring [12].

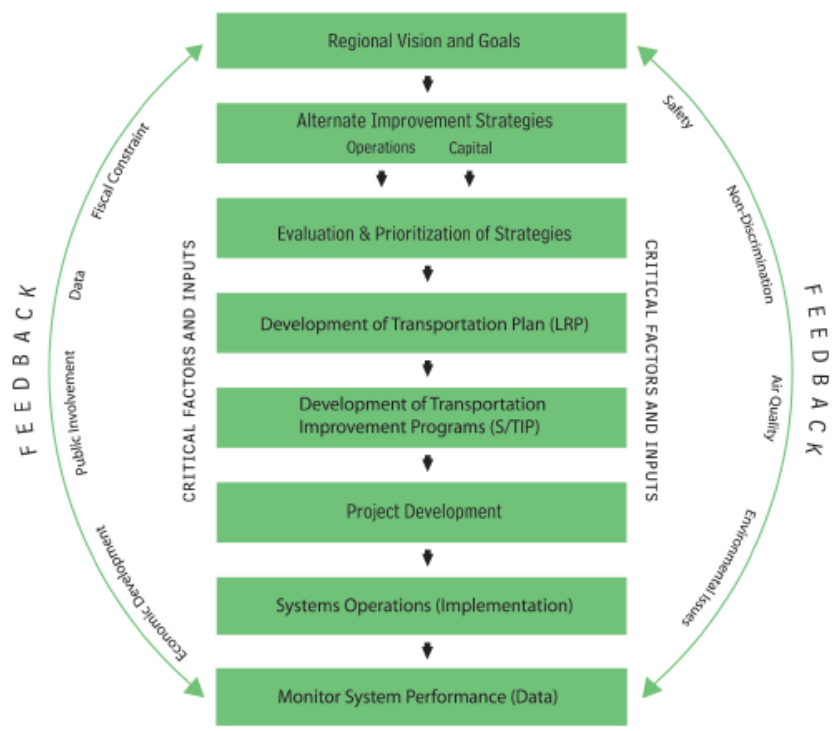

Figure 1: Transportation planning process, Source: [12]

\subsubsection{Funding of ITS projects}

Funding is key to promoting the research, development and deployment of ITS. Adequate funding has been identified as a major factor and pivotal for the successful large scale deployment of ITS. Leading ITS countries which include Japan, South Korea, and Singapore have benefitted from strong government leadership, greater funding, and an ability to successfully forge publicprivate partnerships [13].

Benefits of ITS which include increased reliability, increased productivity, improved safety and security, improved trip planning, reduced traffic congestion, reduced accident and its fatalities, reduced gas consumption, reduced emission etc have been found to far outweigh the costs and justify the investments. Overall, the benefit-cost ratio of systems-operations measures enabled by ITS has been estimated at about 9 to 1 , far above the addition of conventional highway capacity, which has a benefit-cost ratio of 2.7 to 1 [13, 14]. Literature review shows that a great variety of different funding models exist which can be used to develop opportunities for funding ITS projects in Nigeria, these include $[9,11,15,16]$ :
1. External aids: grants and co-funding from agencies like the African Development Bank (ADB) and Economic Community of West African States (ECOWAS) for transportation development programmes.

2. Federal, State and Local Governments transport investment programme: capital grants provided by Federal, State and Local government in the country for investment in ITS programmes.

3. Transport operators funding: investment in vehicles, infrastructure, operating systems and information services by public transport services operators funded with revenue from users and exploitation of owned assets.

4 Private sector concessions: covers various arrangements which make use of private finance for transport projects promoted by the public sector. They include toll revenue, user charges and the financial instruments that provide capital up front (similar to a mortgage) for construction and operation of ITS infrastructure.

5. Public Private Partnership: where a group of public and private sector stakeholders agree to cooperate together in the financing of services of common interest, with each contributing at a level determined by themselves.

6. Joint venture funding: where a group of public and private sector stakeholders come together to form a single legal entity to invest in and deliver ITS transport projects.

7. Special innovation funds: aimed at stimulating innovation to address grand challenges by providing support for new products, services and systems at a critical stage of their development. Selection could be on a competitive basis and the fund may be jointly financed with the private sector.

8. Funding incentives and subsidies: from the public sector to offset user or service provider costs in order to achieve a specific policy goal.

9. Sponsorship: by the private or non-profit sector to offset public sector investment and operational costs in providing infrastructure and services.

10. Special borrowing and investment arrangements: that bridges the gap between the financial cost of a transport project and the revenue which they might generate by facilitating and promoting ways to finance and operate transport projects.

11. Dedicated funding for ITS: ring-fenced funding programmes for ITS infrastructure and services.

\subsubsection{Research and Deployment of Research Products for Optimization of ITS}

Public agencies, universities and research institutes in developed economies establish real-world refinement 
and the new technologies and methods that are developed have been made to thrive through the deployment of prototypes on test roads, vehicles and use in communities [17]. Thus, public agencies in concert with academic and private industry partners in the developing countries should also embark on ITS research and development programs. Robust research programs in any country incorporating a number of activities that directly support ITS deployment will indeed have a catalyzing role in the management of the complexities inherent in urban trip making without the need to necessarily expand the physical fixed facilities.

Efforts targeted at the deployment of ITS smart technologies on existing infrastructure have the possibility and intent of optimizing system performance thereby improving safety, mobility, efficiency, and reliability of the nation's transportation infrastructure. Such optimization effort should include; an integrated approach to synchronize the performance of existing infrastructure through the various transportation system management (TSM) strategies, including implementation of multimodal, intermodal and often cross-jurisdictional systems, services and projects. The performance optimization of fixed-time traffic signalization schemes through informed monitoring and improvement of phase timings or by replacing them with vehicle actuated signalization or coordinated signalization schemes cannot be ruled out. Other TSM measures include the installation of Close Circuit Television (CCTV), use of probe vehicles for surveillance, incident detection and safe monitoring of the roads.

\subsubsection{Performance Evaluation System for ITS Deployment}

Operational performance measures should be incorporated in a deployed ITS. The performance measures provide the parameters with which to answer questions about whether the performance of the transportation system is getting better or worse, instantly or over time; and whether transportation investments are correlated or linked to stated goals and objectives of transportation planning, and most especially in meeting public goals and expectations. Thus, avenues should be created to obtain feedback from the public on deployed ITS facilities, because the concerns and issues of everyone with a stake in transportation would be identified and addressed in the development of ITS policies, programs, and projects being proposed in their communities [12]. Public involvement enhances good decision making, creates awareness and the goodwill of the benefitting community.

The Performance measurement indices of deployed ITS facilities include $[11,12]$ : i. Accessibility: Whether special populations such as the elderly are able to use transportation; whether transportation services provide access for underserved populations to employment sites.

ii. Mobility: Average travel time from origin to destination; change in average travel time for specific origin-destination points; average trip length; percentage of trips per mode (modal split); time lost to congestion; transfer time between modes; percent on-time transit performance.

iii. Economic development: Jobs created and new housing that start in an area as a result of new transportation facilities; new businesses opening along major routes; percent of region's unemployed who cite lack of transportation as principal barrier to employment; economic cost of time lost to congestion.

iv. Quality of life: Environmental and resource consumption; tons of pollution generated; fuel consumption per vehicle kilometre travelled; decrease in wetlands; changes in air quality, land use etc.

v. Safety: Number of crash incidents or economic costs of crashes.

\section{MATERIALS AND METHODS}

\subsection{Research Efforts on Deployment of ITS In Nigeria}

This section highlights the efforts being made by researchers in the University of Ilorin, Ilorin, Nigeria and Federal University of Technology, Minna, Nigeria aimed at improving the effectiveness and efficiency of Transportation Systems in Nigeria. It involves the development and deployment of Advanced Public Transportation System (APTS) and Advanced Traveller Information System (ATIS) categories of the ITS in three major phases.

\subsection{Phase I - Identification of Potential Benefits of ITS in Nigeria}

A study [1] enumerated the hindrances militating against Nigeria in benefiting from ITS potentials to include low level or total absence of either in-vehicle or facility based navigation systems, poor and or unreliable information gathering and communication as well as inadequate traffic analytical computer hardware and software, among others. The authors were however of the opinion that considering the level of technological and technical manpower capability and potentials of Nigeria, the country can and should begin to benefit from ITS and advocated for government and private sector driven policies towards this objective. In addition, trip information management is identified as the most appropriate approach for the prevailing level of technology and at least cost.

Vol. 35. No. 3, July 2016 


\subsection{Phase II - ITS Research Products in Nigeria}

2.2.1. Development of an Advanced Public Transportation System for captive commuters on urban arterials in Ilorin, Nigeria

A software package for Advanced Public Transportation System which has both a Digital Geographic Database (DGD) and Automatic Trip Scheduling System (ATSS) capabilities/functionalities was developed for Ilorin metropolis, Nigeria [17]. The DGD allows the map of the service area to be displayed to the scheduler/operator and the commuters/clients on the computer screen. The ATSS subsystem has the specific objectives of reducing commuters waiting time at bus terminals by automating trip booking thus assuring a passenger of the availability of a bus. The ATSS subsystem also keeps an inventory of passengers and trips made by commuters and the vehicles (carriers). There was however a limitation in the study. Whereas an Advanced Public Transportation System consists of three related technologies: A Digital Geographic Database (DGD), An Automated Trip Scheduling System (ATSS) and Automated Vehicle Location Equipment (AVLE) [17,18], the AVLE component of APTS could not be included in the developed software package. This is because the commercial vehicles and indeed almost all the vehicles in the study area are not installed with AVLE. Again, the insufficiency of the modern day in-vehicle data capture facility to promote the ITS was a major challenge.

\subsubsection{Development of an Advanced Public Transportation System for captive commuters in Minna metropolis, Nigeria}

The study developed, as done for Ilorin, Kwara State, an Advanced Public Transportation System (APTS) software package that serves as an intelligent movement system for captive commuters in Minna, Niger State. The APTS has a Digital Geographic Database (DGD) for route guidance, an Automated Trip Scheduling System (ATSS) for electronic trip booking, an Electronic Ticketing System (ETS) for electronic fare payment and an Automated Passenger Counter (APC) that keeps an inventory of passenger and trips made by commuters and vehicles which operators can analyze for future trip schedule planning.

\subsubsection{Web-based Advanced Traveler Information System for Minna metropolis, Nigeria}

The dearth of detailed and explicit information on transportation routes and systems which are necessary to make informed decisions on a trip have, almost all the times, caused unnecessary delays, anxiety, extra cost and even at times jeopardized the safety of travelers when using the transportation route or system especially for the first time. The development and deployment of Advanced Travelers Information System (ATIS) which is a category of Intelligent Transportation System (ITS) was tried to address this issue. The study developed a web-based ATIS for Minna metropolis in Nigeria. The ATIS provides the route guidance, electronic fare payment system, information on available intercity transport services and hotels, weather condition, traffic flow condition and means of booking for both trips and hotel accommodation. The ATIS improves on the convenience of travelers and is a source of static and dynamic information.

Programming of the website involved the use of different programming languages as no single one was going to very effectively yield the intended product. So for different parts and functionalities, varying programming languages and syntaxes were used. The programming languages used include:

1. Java Script,

2. Hyper Text Mark Up Language (html),

3. Cascading Style Sheet (CSS)

4. Structural Query Language (MySQL),

5. PHP-Hyper Processor,

6. AJAX (Asynchronous Java Script And XML).

The use of the above mentioned programming languages yielded a lot of flexibility in the process of designing the database of the site. Application Programming Interfaces (APIs) which include Google Maps (for Route Guidance) and Open Weather maps (for Weather Condition) were embedded in the development of the website.

\subsection{Phase III - Future Research Works}

With the modest achievements of efforts made in ITS research and development it is obvious that improving the efficiency and modernization of public transportation practice and operations in Nigeria, can be further promoted with future research works. Essentially, in the aspect of trip information management these will include (1) closing the AVLE gap mentioned in Phase II and installation of some test vehicles with AVLE with the sole aim of deploying the APTS technology on the studied corridors and (2) developing a traffic monitoring system to provide real-time information on traffic conditions.

\section{RESULTS AND DISCUSSION}

\subsection{Terminals and Travel Routes}

Based on the outcome of the origin-destination survey, seventeen terminals were identified in the study on Ilorin while the study on Minna revealed five terminals in the study area. The terminals were used to define the routes serviced by the developed softwares; a travel route being a link between two terminals. Sixty travel routes were thus identified for Ilorin while the terminals 
in the study on Minna were used to define the two routes (Route 1 and Route 2) in the study.

The terminals in Ilorin APTS are:

1. Offa Garage Bus Terminal,

2. Oja Oba Bus Terminal,

3. Unilorin (PS) Bus Terminal,

4. Asa Dam Bus Terminal

5. Airport Bus Terminal,

6. Tipper Garage Bus Terminal,

7. Geri Alimi Bus Terminal,

8. Pipeline Bus Terminal,

9. Gaa Akanbi Bus Terminal,

10. Taiwo Oke Bus Terminal

11. Unity Bus Terminal

12. Post Office Bus Terminal

13. Challenge Bus Terminal

14. Basin Bus Terminal

15. Fate Bus Terminal

16. Tanke junction Bus Terminal

17. Unilorin (mini campus) Bus Terminal.

The terminals in Minna study are:

1. Bosso FUT Bus Park,

2. Dutsen Kura Junction,

3. Kpakungu Bus Park,

4. Gidan Kwano FUT Gate Bus Stop

5. Gidan Kwano FUT Bus Park.

The DGD of the travel routes as displayed to the user are shown in Fig. 2 for Ilorin and Fig. 3 for Minna.

\subsection{Departure Time Survey}

In the APTS for Ilorin; on Route 1 which is from Unilorin P.S Terminal to Challenge Bus Terminal, a total of 122 , 116 , and 122 trips were recorded on day 1 , day 2 , and day 3 , respectively, while on Route 2 which is from Post Office Terminal to Oja Oba Terminal, 63, 70, and 64 trips were recorded on day 1 , day 2 , and day 3 , respectively. The collected data from the 3-day departure time survey were analyzed and summarized as given in Tables 2 and 3. Table 2 shows the number of buses that depart Unilorin PS Terminal to Challenge Bus Terminal (Route 1) within the specified period of the day, while Table 3 shows the number of buses that depart Post Office Terminal for Oja Oba Terminal (Route 2) within the specified period of the day. From Table 3, since an average of 11 buses (filled to capacity) depart between $7.00 \mathrm{am}$ and $9.00 \mathrm{am}$, it is deduced that eleven buses will be needed along Route 1 to meet the travel demand of commuters along the route, and the buses will need to be supplied between the period of $7.00 \mathrm{am}$ and $9.00 \mathrm{am}$ at 10 min interval. Similarly, 14 buses will be needed between the period of 9.00 am and 11.00 am at $9 \mathrm{~min}$ interval, 15 buses between the period of $11.00 \mathrm{am}$ and $1.00 \mathrm{pm}$ at $8 \mathrm{~min}$ interval, 23 buses between $1.00 \mathrm{pm}$ and $3.00 \mathrm{pm}$ at $5 \mathrm{~min}$ interval, 32 buses between $3.00 \mathrm{pm}$ and $5.00 \mathrm{pm}$ at $4 \mathrm{~min}$ interval, and 27 buses between the period of $5.00 \mathrm{pm}$ and $7.00 \mathrm{pm}$ at $4 \mathrm{~min}$ interval. From Table 4, an average of 19 buses at 6 min interval can be economically supplied between 7.00 am and $9.00 \mathrm{am}$, eight buses at $15 \mathrm{~min}$ interval between $9.00 \mathrm{am}$ and $11.00 \mathrm{am}$, nine buses between $11.00 \mathrm{am}$ and $1.00 \mathrm{pm}$ at 13 min interval, another nine buses between $1.00 \mathrm{pm}$ and $3.00 \mathrm{pm}$ at $13 \mathrm{~min}$ interval; seven buses between $3.00 \mathrm{pm}$ and $5.00 \mathrm{pm}$ at $17 \mathrm{~min}$ interval, and 17 buses between $5.00 \mathrm{pm}$ and $7.00 \mathrm{pm}$ at $7 \mathrm{~min}$ interval. The approach described above is used to determine and generate the data on the required number of buses and their departure schedule that will be adequate to meet the demand of the commuting community along the remaining routes [17].

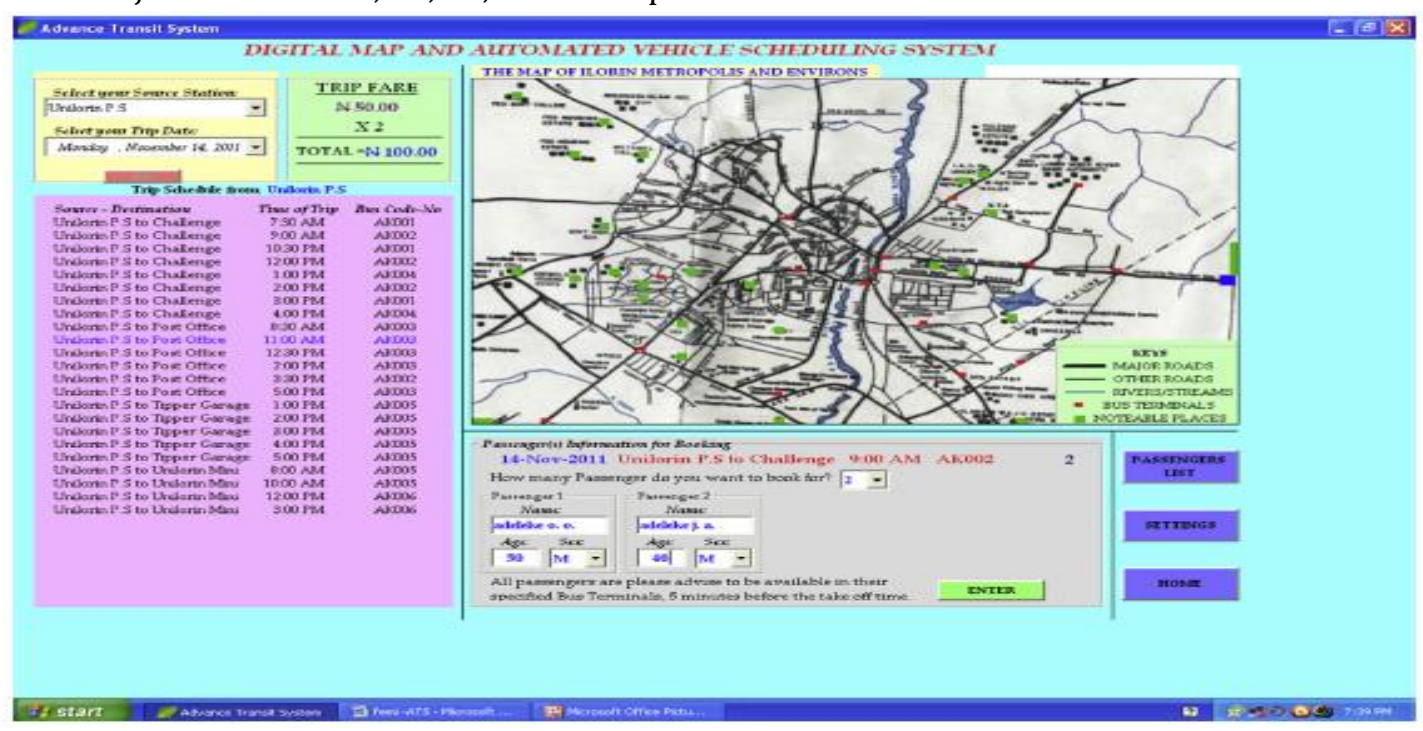

Figure 2: Book trip and view map page, Source: [17] 


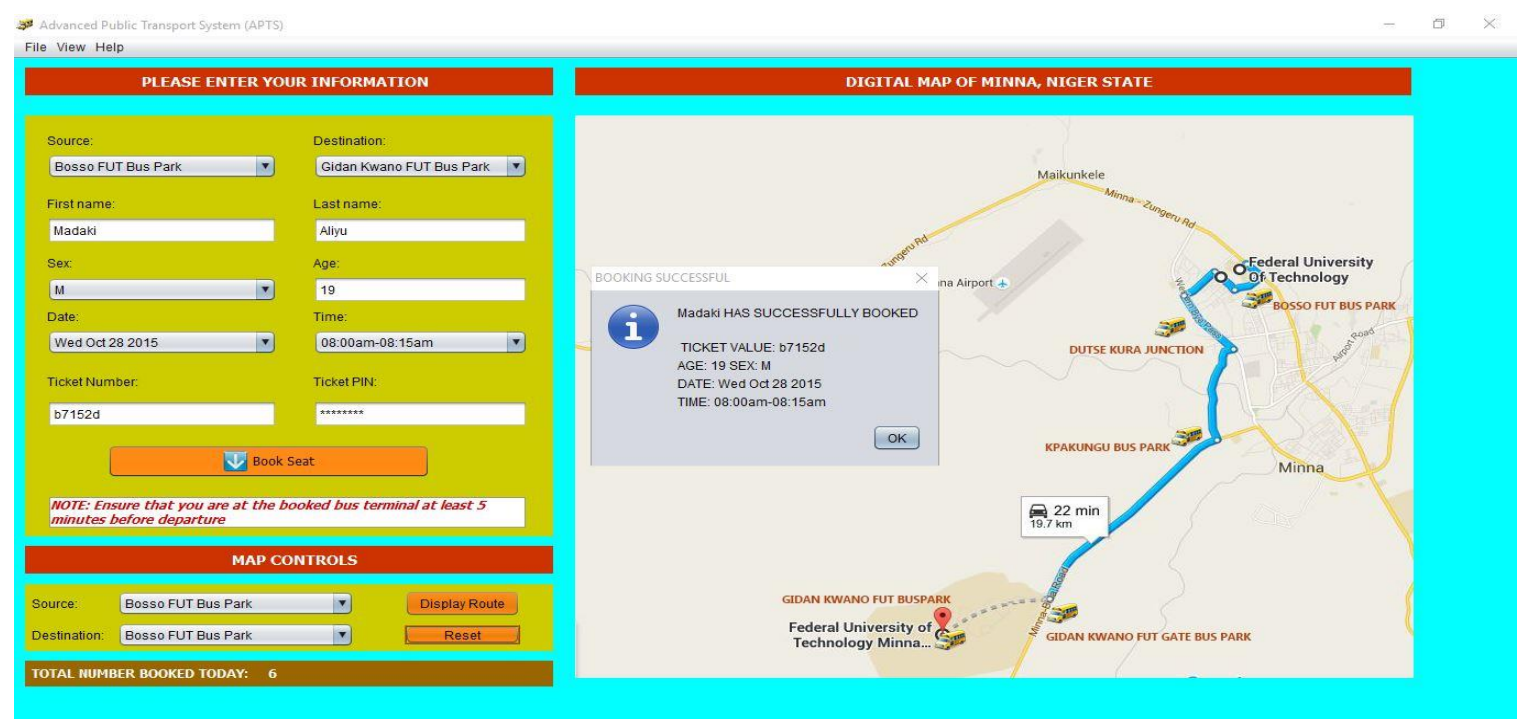

Figure 3: The Home Page of the APTS developed for Minna metropolis

Table 2: Summary of number of buses and departure periods for Route 1 (Unilorin PS Terminal to Challenge Bus Terminal, Source: [17]

\begin{tabular}{ccccc}
\hline \multirow{2}{*}{ Departure times } & \multicolumn{3}{c}{ Number of 18-seater buses } & \multirow{2}{*}{ Average number of departures (veh) } \\
\cline { 2 - 4 } & Day 1 (veh) & Day 2 (veh) & Day 3 (veh) $n$ & 11 \\
$7.00-9.00 \mathrm{am}$ & 10 & 10 & 12 & 14 \\
$9.00-11.00 \mathrm{am}$ & 15 & 12 & 14 & 15 \\
$11.00-1.00 \mathrm{pm}$ & 15 & 13 & 16 & 23 \\
$1.00-3.00 \mathrm{pm}$ & 24 & 22 & 24 & 32 \\
$3.00-5.00 \mathrm{pm}$ & 30 & 35 & 30 & 27 \\
$5.00-7.00 \mathrm{pm}$ & 25 & 26 & 29 & \\
\hline
\end{tabular}

Table 3: Summary of number of buses and departure periods for Route 2 (Post Office Terminal to Oja Oba Terminal), Source: [17]

\begin{tabular}{|c|c|c|c|c|}
\hline \multirow{2}{*}{ Departure times } & \multicolumn{3}{|c|}{ Number of 18-seater buses } & \multirow{2}{*}{ Average number of departures (veh) } \\
\hline & Day 1 (veh) & Day 2 (veh) & Day 3 (veh) & \\
\hline $7.00-9.00 \mathrm{am}$ & 18 & 20 & 19 & 19 \\
\hline $9.00-11.00 \mathrm{am}$ & 7 & 6 & 12 & 8 \\
\hline $11.00-1.00 \mathrm{pm}$ & 9 & 7 & 12 & 9 \\
\hline $1.00-3.00 \mathrm{pm}$ & 9 & 10 & 9 & 9 \\
\hline $3.00-5.00 \mathrm{pm}$ & 6 & 7 & 9 & 7 \\
\hline $5.00-7.00 \mathrm{pm}$ & 14 & 21 & 16 & 17 \\
\hline
\end{tabular}

In the study on Minna APTS, Table 4 shows the number of seats/buses that depart Bosso FUT Bus Park to Gidan Kwano FUT Bus Stop (Route 1) within the specified period of the day, while Table 5 shows the number of buses/seats that depart Gidan Kwano FUT Gate Bus Stop to Gidan Kwano FUT Bus Park (Route 2) within the specified period of the day.

In Table 4, since an average of 746 seats are needed between 06:30 am and 08:30 am, it is deduced that 746 seats made up of either 15 of 50 -seaters or 21 of 35 -seaters or 42 of 18 -seaters or their equivalent, should be provided along Route 1 to meet the travel demand of commuters along the route between the period of 06:30 am and 08:30 am. Similarly, 564 seats will be needed between the period of $08: 30$ am and $12: 30 \mathrm{pm}, 324$ between the period of 12:30 pm and
02:30 pm, 152 seats between 02:30 pm and 04:30 pm, 189 between 02:30 pm and 04:30 pm, and 188 seats between the period of 04:30 pm and 06:30 pm.

Table 5 shows that an average of 201 seats is needed between 06:30 am and 08:30 am. Therefore 201 seats should be provided comprising of either of 34 of 6 seaters taxi or 50 of 4 -seaters taxi or their equivalent can be economically supplied on route 2 between 06:30 am and 08:30 am, 240 seats between 08:30 am and 10:30 am, 72 seats between 10:30 am and 12:30 pm, 42 seats between 12:30 pm and 02:30 pm; 10 seats between $02: 30 \mathrm{pm}$ and $04: 30 \mathrm{pm}$, and 26 seats between 04:30 pm and 06:30 pm.

The obtained data from the departure time surveys were used to develop the ATSS which automates trip bookings and keeps an inventory of passengers and 
trips made by commuters and the vehicles (carriers) as shown in Figure 4 and Figure 5 respectively in the case of Ilorin APTS. Figure 6 shows the booking and ticketing process in Minna APTS.

Table 4: Summary of number of seats/buses and departure periods for Route 1 (Bosso FUT Bus Park to FUT Gidan Kwano Bus Terminal)

\begin{tabular}{|c|c|c|c|c|c|}
\hline Departure time & Day 1 & Day 2 & Day 3 & $\begin{array}{l}\text { Number of sea } \\
\text { Average number of seats }\end{array}$ & Average number of buses \\
\hline 06:30 - 08:30 am & 676 & 690 & 871 & 746 & 15 of 50 -seaters or its equivalent \\
\hline 08:30 - 10:30 am & 589 & 503 & 600 & 564 & 12 of 50 -seaters or its equivalent \\
\hline $10: 30-12: 30 \mathrm{pm}$ & 230 & 466 & 275 & 324 & 9 of 35-seaters or its equivalent \\
\hline $12: 30-02: 30 \mathrm{pm}$ & 160 & 206 & 89 & 152 & 8 of 18 -seaters or its equivalent \\
\hline $02: 30-04: 30 \mathrm{pm}$ & 126 & 86 & 54 & 89 & 5 of 18 -seaters or its equivalent \\
\hline $04: 30-06: 30 \mathrm{pm}$ & 162 & 328 & 72 & 188 & 10 of 18 -seaters or its equivalent \\
\hline
\end{tabular}

Table 5: Summary of number of seats/buses and departure periods for Route 2 (Gidan Kwano FUT Gate Bus Stop Terminal to FUT Gidan Kwano Bus Terminal).

\begin{tabular}{lccccc}
\hline Departure time & \multicolumn{9}{c}{ Number of seats } & & \\
& Day 1 & Day 2 & Day 3 & Average number of seats & Average number of buses \\
\hline 06:30 - 08:30 am & 220 & 188 & 194 & 201 & 34 of 6-seaters or its equivalent \\
08:30 - 10:30 am & 280 & 202 & 236 & 240 & 40 of 6-seaters or its equivalent \\
10:30 - 12:30 pm & 90 & 46 & 78 & 72 & 18 of 4-seaters or its equivalent \\
12:30 - 02:30 pm & 52 & 42 & 30 & 42 & 11 of 4-seaters or its equivalent \\
02:30 - 04:30 pm & 16 & 10 & 04 & 10 & 3 of 4-seaters or its equivalent \\
04:30- 06:30 pm & 26 & 28 & 24 & 26 & 7 of 4-seaters or its equivalent \\
\hline
\end{tabular}

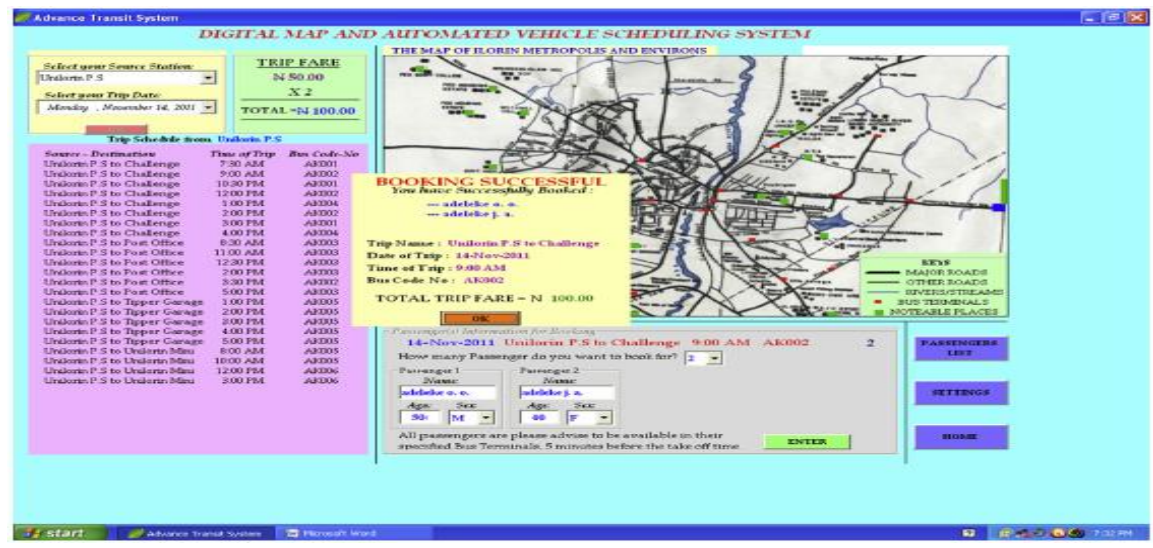

Figure 4: Window showing a successful booking Source: [17]

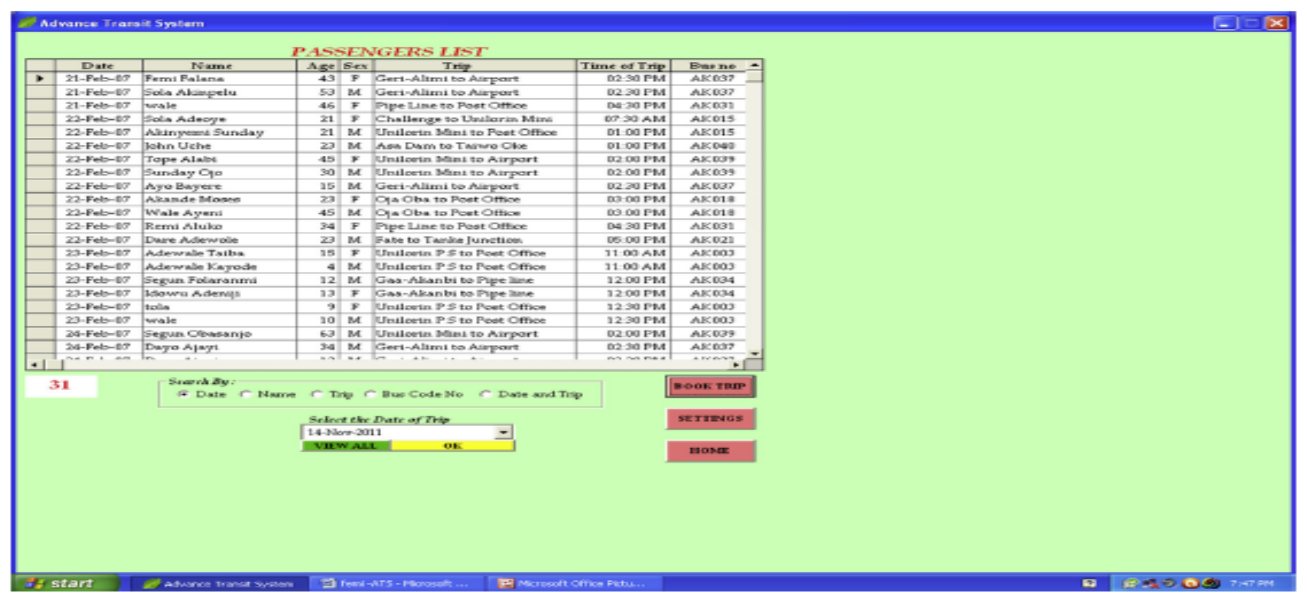

Figure 5: Passenger list database window

Source: [17] 


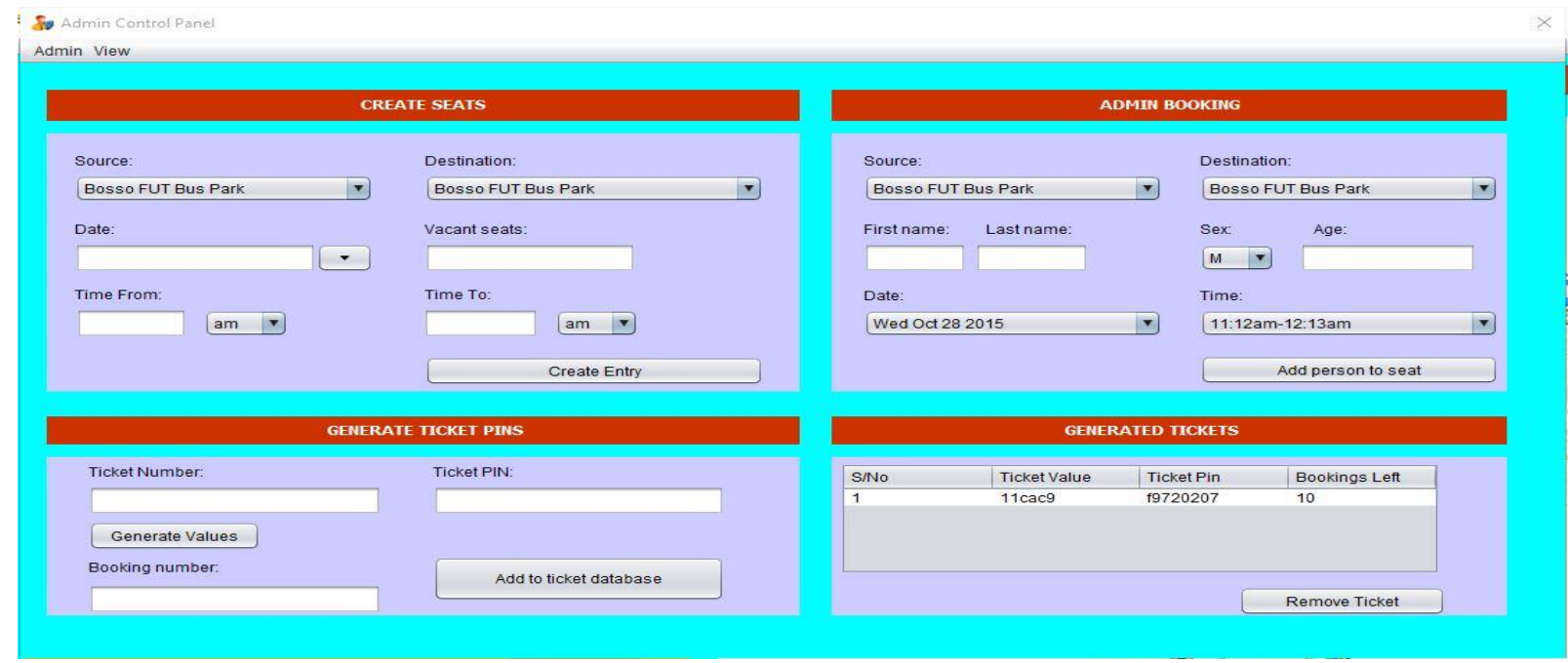

Figure 6: 'Admin Panel' of the APTS for Minna

\subsection{ATIS Route Guidance and Bookings}

Data on bus routes used as information in the Trip Booking of the ATIS include those shown in Table 6 for Transit A and Transit B respectively. The home page of the ATIS website is shown in Fig. 7. Fig. 8 is the screenprint showing necessary information for trip booking while Fig. 9 is a drive direction as displayed by the Google Map embedded in the developed website.

\subsection{Travel Demand Forecast}

Equations 1 and 2 were obtained from the populations (for 2010/2011 - 2014/2015 sessions) of University of Ilorin (Unilorin) and FUT Minna respectively as shown in Table 7 using regression analyses. The equations were subsequently used to determine the projected populations of the two communities as shown in Table 7 and thereafter forecast the travel demands (Garber and Hoel, ) in 2025, 2035 and 2040 (i.e. the next 10, 20 and 25 years) for Route 1 in the case of Ilorin APTS and the two routes in Minna APTS.

$$
\begin{aligned}
& y=544.33 x^{2}-3089 x^{2}+6341 x+28048 \\
& y=108 x^{2}-250 x+15317
\end{aligned}
$$

In (1) and (2) $\mathrm{y}$ is the population and $\mathrm{x}$ is the number of years.

\begin{tabular}{|c|c|c|c|}
\hline \multicolumn{2}{|c|}{ Transit A } & \multicolumn{2}{|c|}{ Transit B } \\
\hline Route & $\begin{array}{l}\text { Transport Fare } \\
\text { Per Person (A) }\end{array}$ & Route & $\begin{array}{l}\text { Transport Fare } \\
\text { Per Person (A) }\end{array}$ \\
\hline Minna - Enugu & 3,000 & Minna - Ilorin & 2,200 \\
\hline Minna - Ibadan & 4,000 & Minna - Lagos & 4,500 \\
\hline Minna - Ilorin & 3,200 & $\begin{array}{l}\text { Minna - } \\
\text { Kaduna }\end{array}$ & 1,000 \\
\hline Minna - Lagos & 3,800 & Minna - Kano & 2,000 \\
\hline Minna - Nsukka & 2,400 & $\begin{array}{l}\text { Minna - } \\
\text { Makurdi }\end{array}$ & 2,500 \\
\hline Minna - Onitsha & 4,000 & Minna - Jos & 2,500 \\
\hline Minna - Owerri & 3,000 & $\begin{array}{l}\text { IVInna- } \\
\text { Bauchi }\end{array}$ & 2,800 \\
\hline $\begin{array}{l}\text { Minna - Port } \\
\text { Harcourt }\end{array}$ & 3,500 & $\begin{array}{l}\text { Minna - } \\
\text { Sokoto }\end{array}$ & 3,200 \\
\hline $\begin{array}{l}\text { Minna - } \\
\text { Abakaliki }\end{array}$ & 3,500 & $\begin{array}{l}\text { Minna - } \\
\text { Katsina }\end{array}$ & 2,500 \\
\hline Minna - Aba & 3,900 & Minna - Bida & 400 \\
\hline Minna - Abuja & 350 & Minna - Suleja & 450 \\
\hline
\end{tabular}

Table 6: Data on Bus Routes
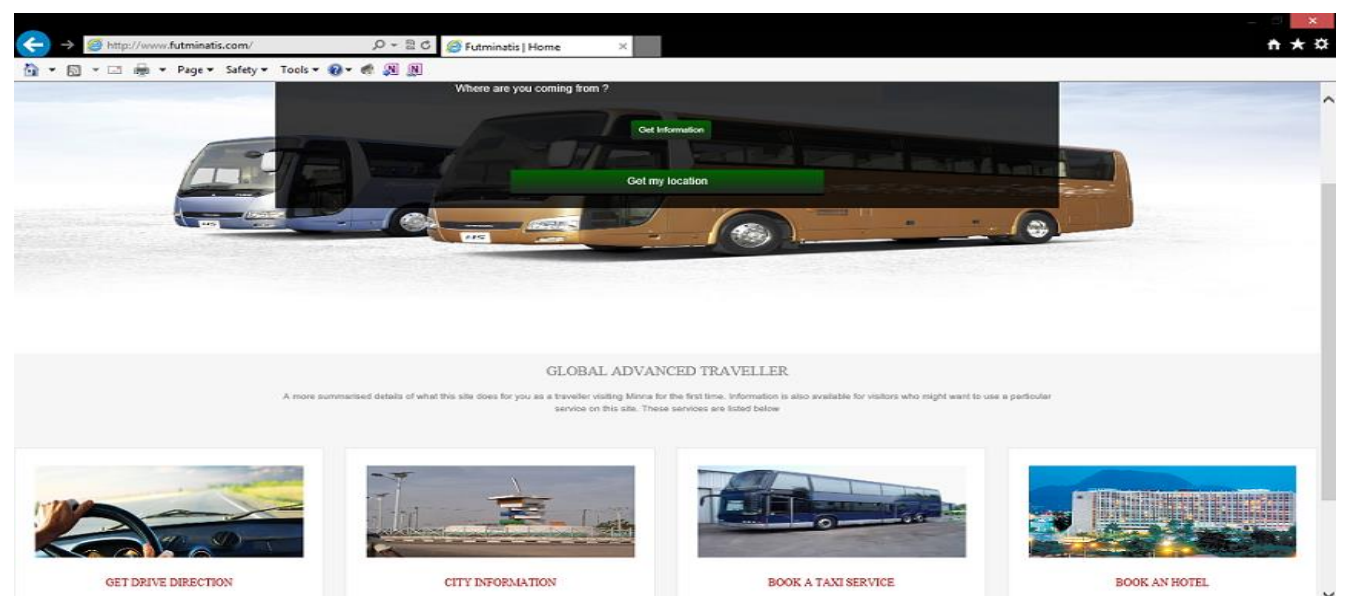

Figure 7: Screen print of homepage of ATIS for Minna 


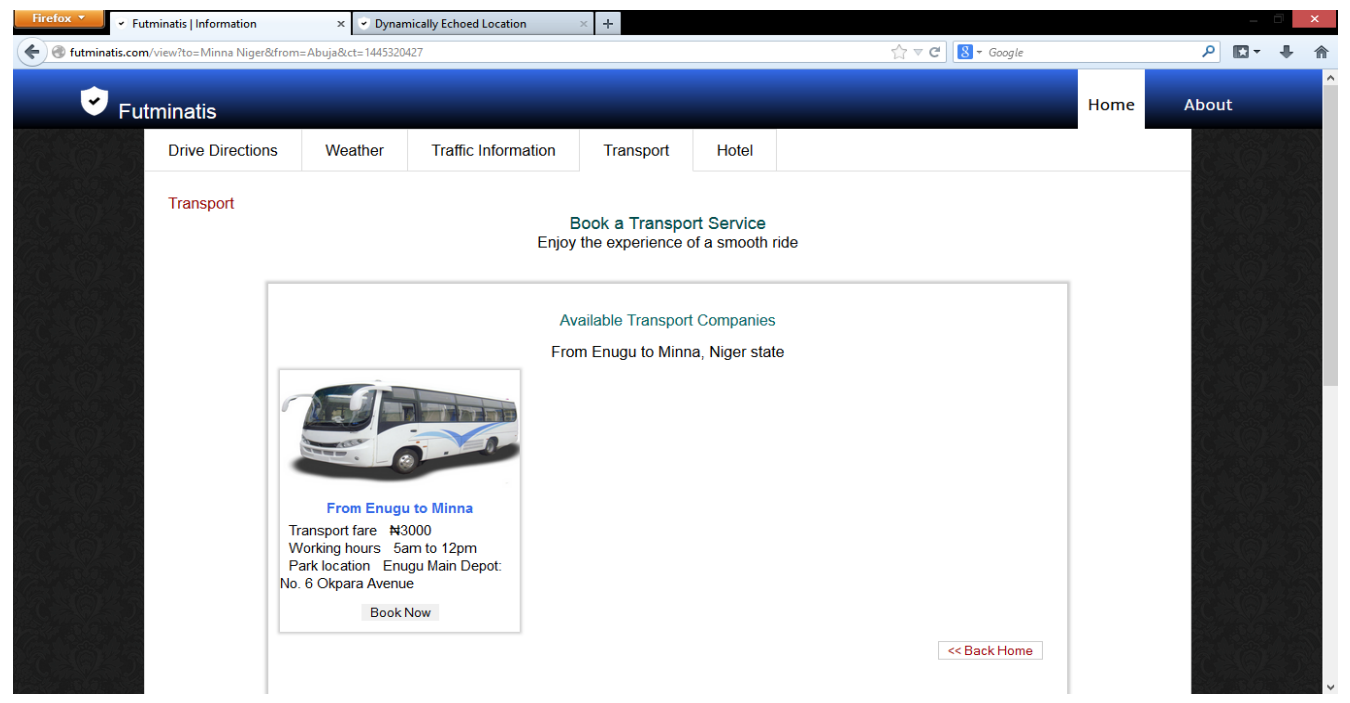

Figure 8: Screen print showing information on trip booking

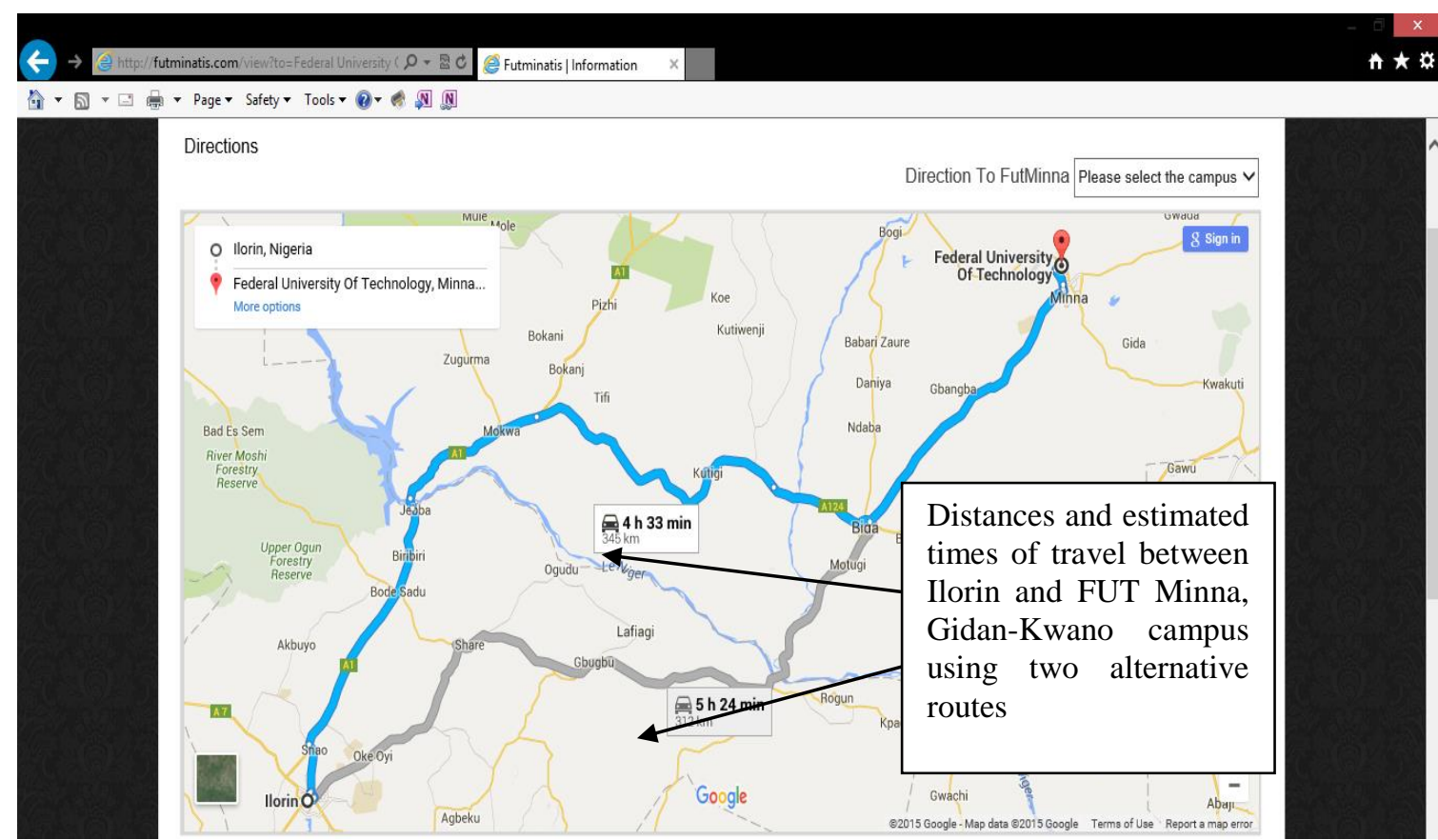

Figure 9: Screen print of drive directions from Ilorin to F.U.T Minna Bosso Campus in the ATIS for Minna

\section{Table 7: Populations of Unilorin and FUT Minna}

\begin{tabular}{ccc}
\hline Year & Unilorin & FUT Minna \\
\hline $2010 / 2011$ & 31,860 & 15282 \\
$2011 / 2012$ & 32,665 & 14801 \\
$2012 / 2013$ & 34060 & 16239 \\
$2013 / 2014$ & 38759 & 15559 \\
$2014 / 2015$ & 50580 & 16893 \\
$2024 / 2025$ & 1265258 & 35,867 \\
$2034 / 2035$ & 6761114 & 76567 \\
$2039 / 2040$ & 12135100 & 105017 \\
\hline
\end{tabular}

Source: Adapted [20, 21, 22, 23, 24, 25, 26, 27, 28, 29]

Relating the data in Tables 2 - Table 5 to the projected populations of the two communities; Route 1 in Ilorin
APTS will in 2015 need as many as 37 times the present fleet size, 199 times the present fleet size in 2035 and 356 times the size in 2040 with corresponding increase in the capacities of fixed facilities to meet the demands of commuters. The two routes in the case of Minna APTS will need as many as twice the present fleet size in 2025, four and half times the present fleet size in 2035 and six times the present fleet size in 2040, to meet the demands of commuters.

\subsection{Deployment of Developed ITS Research Products} The deployment of the developed APTS in the two cities of Ilorin and Minna will need the cooperation of 
commercial transport service operators, who provide services along the studied corridors. This includes private transport service providers and the University of Ilorin Bus Management Board in the case of Ilorin and private transport service providers, the Niger State Transport Authority and the FUT Minna Bus Management Board in the case of Minna. For the electronic payment using ATM as provided in the ATIS to be fully functional appropriate financial institutions will be involved.

The potential benefits derivable from the research products include the following:

1. Trip planning by commuters is enhanced as the assurance of availability of bus seat is guaranteed once a passenger has been successfully booked for a trip

2. Better predictable time of departure and arrival of vehicles at bus stop resulting from bus scheduling

3. The electronic fare payment/ticketing encourages e-transact and will reduce if not eliminate the present payment by cash at the bus entrance which often leads to disorderliness of commuters especially when the commuter does not have the exact transport fare which will necessitate collecting a balance/change which may not be available with the conductor.

4. The ATIS promotes route guidance and information on estimated travel time, provides travelers information on intercity transport services to and from Minna and available hotel accommodation in the city among others. Bookings for hotels and trips can also be made on line.

\subsection{Guidebook}

Guidebook should be developed to inform transportation operators and engineers of available ITS technologies and to provide them with useful guidance on how to evaluate, select, and effectively deploy ITS technologies that will best meet the needs of the roadway users in Nigeria $[11,14]$.

\subsection{Capacity Building}

ITS projects involve application of engineering, electronics and computer information technology principles. Thus, the human resource needs for ITS projects vary significantly from the traditional transportation engineering projects in terms of facility, construction and operations to the sophisticated ICT utilization. There is therefore the need to provide necessary training for staff on the planning, design, installation, operation and maintenance of ITS facilities. The experience from the research efforts affirms the need for synergy of the skills of the transportation engineers, ICT resource persons, transportation managers and planners among others to promote ITS.

\subsection{Technical Integration}

There should be a forum for transportation stakeholders for discussing issues on ITS. Systems should be developed that allow information sharing and coordination among federal, state and local government agencies and private firms that would use the avenue for pursuing ITS market opportunities.

\section{CONCLUSION}

Transportation in Nigeria can be improved through the deployment of Intelligent Transportation System (ITS) on our transport infrastructures. The ATPS and ATIS research products are demonstration of efforts geared towards the deployment of ITS in enhancing transportation in Nigeria. The ITS research products and others should be developed, deployed and their performance evaluated for improved efficiency.

\section{REFERENCES}

[1] Jimoh, Y. A. and Adeleke, O.O. 'Potential Benefits of Intelligent Transportation System (ITS)in Nigeria', USEP: Journal of Research in Civil Engineering 2 (1), 2005, pp 46-56.

[2] Naqvi, H.M. Applications of ITS in Bus Transit. National Workshop on Intelligent Transportation System, Pune, India, 25-26 June, 2010.

[3] Vieira, V., Salgado, A.C., Tedesco, P., Times, V., Ferraz, C., Huzita, H., Chaves, A.P., Steinmacher, I. 'The UbiBus Project: Using Context and Ubiquitous Computing to Build Advanced Public Transportation Systems to Support Bus Passengers'. http://www.cin.ufpe.br/ ubibus/ artigos/VieiraEtAl UBIBUS SBSI2012.pdf Accessed on February. 24, 2013.

[4] Shankar, K.V.R.R. 'Applications of Advanced Technologies to Transportation Systems in Indian Context', International Journal of Earth Sciences and Engineering 04 (06 SPL), 2011, pp 394-397.

[5] US Department of Transportation. Advanced Public Transportation Systems: The State of the Art, Update '94, US Department of Transportation, 1994.

[6] World Resource Institute. Modernising Public Transportation: Lessons Learned from Major Bus Improvements in Latin America and Asia, The WRI Center for Sustainable Transport, USA, 2010. 
[7] Vanajakshi, L. Ramadurai, G. Anand, A. 'Intelligent Transportation Systems, Synthesis Report on ITS Including Issues and Challenges in India', IIT Madras, India, December 2010. <http://coeut.iitm.ac.in/ITS_synthesis.pdf>Accesse d on February 24, 2013.

[8] Adebambo S. and Adebayo, I. T. 'Impact of Bus Rapid Transit System (BRT) On Passengers' Satisfaction in Lagos Metropolis, Nigeria', International Journal of Creativity and Technical Development, Vol. 1 No. 1 - 3, 2009, pp. 106-122.

[9] Efimenko, D. B. ITS-related Aspects of Development of Urban Transport Systems. Moscow State Automobile and Road Technical University Department, Russia.

[10] Ben-Akiva, M. Intelligent Transportation Systems (ITS) and the Impact of Traveler Information \& Emerging Themes in Transportation Economics and Policy. Massachusetts Institute of Technology, USA.

[11] U.S. Department of Transportation, Intelligent Transportation Systems Benefits, Costs, Deployment, and Lessons Learned, 2008 Update, U.S. Department of Transportation 2008.

[12] U.S. Department of Transportation, The Transportation Planning Process: Key Issues, U.S. Department of Transportation, 2005.

[13] Ezell, S. 'Bringing U.S. Roads into the 21st Century'. Issues in Science and Technology 26, No. 4 (Summer 2010).

[14] Elizer, M. 'Strategies and Outlook for ITS Financing'. http://nationalruralitsconference.org/downloads/ Presentations12/B1 Elizer.pdf Accessed on February 12, 2016.

[15] European Commission. Study Regarding Guideline for Public Funding of Intelligent Transportation Systems, Final Report, European Commission/DG MOVE, 2011.

[16] Shladover, S. Dahlgren, J. Recker, W. Ritchie, S. Varaiya P. and Conroy, P. 'Intelligent Transportation Systems Research Products for Public Works Professionals', Public Works Management \& Policy,
Vol. 5 No. 1, July 2000 3-13, Sage Publications, Inc., USA 2000.

[17] Adeleke, 0. O. Jimoh, Y. A. and Akinpelu, M. A. 'Development of an Advanced Public Transportation System for Captive Commuters on Urban Arterials in Ilorin, Nigeria'. Alexandria Engineering Journal, Vol. 52, 2013, pp. 447-454.

[18] Chira-chavala T. and Venter, C. Advanced Paratransit System: an Application of Digital Map, Automated Vehicle Scheduling and Vehicle Location System, Institute of Transportation Studies, University of California, Berkeley, 1997.

[19] Garber N. J. and Hoel, L. A. Traffic and Highway Engineering. Centage Learning, 2010.

[20] University of Ilorin 2010/2011 Annual Report. University of Ilorin, Ilorin, Nigeria.

[21] University of Ilorin 2011/2012 Annual Report. University of Ilorin, Ilorin, Nigeria.

[22] University of Ilorin 2012/2013 Annual Report. University of Ilorin, Ilorin, Nigeria.

[23] University of Ilorin 2013/2014 Annual Report. University of Ilorin, Ilorin, Nigeria.

[24] University of Ilorin 2014/2015 Annual Report. University of Ilorin, Ilorin, Nigeria.

[25] Federal University of Technology, Minna 2010/2011 Annual Report, Fed. Univ. of Tech, Minna, Nigeria.

[26] Federal University of Technology, Minna 2011/2012 Annual Report, Fed. Univ. of Tech, Minna, Nigeria.

[27] Federal University of Technology, Minna 2012/2013 Annual Report, Fed. Univ. of Tech, Minna, Nigeria.

[28] Federal University of Technology, Minna 2013/2014 Annual Report, Fed. Univ. of Tech, Minna, Nigeria.

[29] Federal University of Technology, Minna 2014/2015 Annual Report, Fed. Univ. of Tech, Minna, Nigeria. 